\title{
Phylogenetic relationships among algae based on complete large-subunit rRNA sequences
}

\footnotetext{
1 Department of Biochemistry, University of Antwerp (UIA), Universiteitsplein 1, B-2610 Wilrijk, Belgium

2 Department of Microbiology, Institute of Tropical Medicine, Nationalestraat 155, B-2000 Antwerpen, Belgium

3 Department of Biology, University of Konstanz, D-78457 Konstanz, Germany
}

\author{
Abdelghani Ben Ali, ${ }^{1}$ Raymond De Baere, ${ }^{1}$ Gert Van der Auwera, ${ }^{2}$ \\ Rupert De Wachter ${ }^{1}$ and Yves Van de Peer ${ }^{3}$
}

Author for correspondence: Yves Van de Peer. Tel: +49 753188 2763. Fax: +49 7531883018. e-mail: Yves.Vandepeer@uni-konstanz.de

\begin{abstract}
The complete or nearly complete large-subunit rRNA (LSU rRNA) sequences were determined for representatives of several algal groups such as the chlorarachniophytes, cryptomonads, haptophytes, bacillariophytes, dictyochophytes and pelagophytes. Our aim was to study the phylogenetic position and relationships of the different groups of algae, and in particular to study the relationships among the different classes of heterokont algae. In LSU rRNA phylogenies, the chlorarachniophytes, cryptomonads and haptophytes seem to form independent evolutionary lineages, for which a specific relationship with any of the other eukaryotic taxa cannot be demonstrated. This is in accordance with phylogenies inferred on the basis of the smallsubunit rRNA (SSU rRNA). Regarding the heterokont algae, which form a wellsupported monophyletic lineage on the basis of LSU rRNA, resolution between the different classes could be improved by combining the SSU and LSU rRNA data. Based on a concatenated alignment of both molecules, the phaeophytes and the xanthophytes are sister taxa, as well as the pelagophytes and the dictyochophytes, and the chrysophytes and the eustigmatophytes. All these sister group relationships are highly supported by bootstrap analysis and by different methods of tree construction.
\end{abstract}

Keywords: heterokont algae, cryptophytes, chlorarachniophytes, haptophytes, large-subunit rRNA (LSU rRNA)

\section{INTRODUCTION}

Generally, on the basis of pigmentation, three main eukaryotic algal groups have been discerned, namely the chlorophytes or green algae (characterized by the presence of chlorophyll $a$ and $b$ ), the rhodophytes or red algae (chlorophyll $a$ and phycobilins), and the chromophytes or yellow-brown algae (chlorophyll $a$ and $c$, and absence of chlorophyll $b$ ). The latter group, which is polyphyletic, is further subdivided into four taxa, namely the cryptophytes, the haptophytes, the dinoflagellates and the heterokont algae, on the basis of pigmentation and plastid ultrastructure, flagellar apparatus and small-subunit rRNA (SSU rRNA)

This paper was presented at the XIIIth meeting of the International Society for Evolutionary Protistology in České Budějovice, Czech Republic, 31 July-4 August 2000.

Abbreviations: LSU RNA, large-subunit rRNA; NM, nucleomorph; SSU RNA, small-subunit rRNA. phylogenies (Whatley, 1989; Bhattacharya et al., 1992; Leipe et al., 1994; Cavalier-Smith et al., 1994a; Medlin et al., 1995).

The cryptophytes or cryptomonads (Gillot, 1990) are unicellular biflagellated organisms for which the evolutionary history is unclear and controversial. In previous studies, they have been phylogenetically positioned with chlorobionts (Eschbach et al., 1991), other chromophytes (Cavalier-Smith et al., 1994a), glaucocystophytes (Bhattacharya et al., 1995a; Ragan \& Gutell, 1995; Van de Peer et al., 1996a) and Acanthamoeba (McFadden, 1993). The haptophytes or prymnesiophytes (Green et al., 1990) are unicellular flagellate cells, characterized by a filiform organelle associated with the flagella, called the haptonema. Also for this group of organisms, the phylogenetic status is rather unclear (Daugbjerg \& Andersen, 1997a; and references therein). The heterokont algae, also referred to as 'stramenochromes' (Leipe et al., 1994) and 'Ochrista' (Cavalier-Smith et al., 1994b), consist 
Table 1. The different algal taxa, classified on the basis of their main pigments

Numbers between brackets indicate the number of membranes surrounding the plastids.

\begin{tabular}{|c|c|c|}
\hline \multicolumn{3}{|c|}{ Algae with: } \\
\hline Chlorophyll $a$ and $b$ & Chlorophyll $a$ and phycobilins & Chlorophyll $a$ and $c$ \\
\hline Chlorophytes (2) & Rhodophytes (2) & Cryptophytes* (4) \\
\hline Chlorarachniophytes (4) & Glaucophytes (2) & Haptophytes (4) \\
\hline Euglenophytes $\dagger(3)$ & & Dinoflagellates (3) \\
\hline & & Heterokont algae: (4) \\
\hline & & Bacillariophytes \\
\hline & & Chrysophytes \\
\hline & & Dictyochophytes \\
\hline & & Eustigmatophytes \\
\hline & & Pelagophytes \\
\hline & & Phaeophytes \\
\hline & & Phaeothamniophytes \\
\hline & & Raphidophytes \\
\hline & & Synurophytest \\
\hline & & Xanthophytes \\
\hline
\end{tabular}

* Although the cryptophytes are classified as algae that contain chlorophyll $a$ and $c$, they also contain phycobilins as accessory pigments. Furthermore, they obtained their plastids by engulfing a eukaryotic alga that most probably was related to the red algae (see text).

$\uparrow$ Euglenophytes are included in the table, although their phylogenetic position is not discussed here. The phylogenetic position of the euglenophytes is controversial and on the basis of rRNA data, Euglena and relatives, which share a common origin with the kinetoplastids, usually branch off well before the other 'crown' taxa. On the contrary, on the basis of protein data, Euglena and the kinetoplastids diverge much later (Baldauf et al., 2000; Van de Peer et al., 2000a).

$\$$ No LSU rRNA data are available yet for these organisms.

of different subgroups that share morphological features such as the possession of tripartite tubular flagellar hairs, similar flagellar anchorage systems (based on four microtubular roots) and electrondense mitochondria with short tubular cristae (Patterson, 1989). The major classes in this group comprised the phaeophytes, chrysophytes, synurophytes, xanthophytes, eustigmatophytes, raphidophytes, bacillariophytes, dictyochophytes, pelagophytes and phaeothamniophytes (Hibberd \& Leedale, 1970, 1971, 1972; Ettl, 1978; Silva, 1980; Andersen, 1987; Heywood, 1990; Andersen et al., 1993, 1998, 1999; Potter et al., 1997; Bailey et al., 1998). The heterokont algae are thus a diverse assemblage of many different smaller groups of algae. The evolutionary relationships between these different groups have been widely studied on the basis of SSU rRNA sequences (Ariztia et al., 1991; Bhattacharya et al., 1992; Andersen et al., 1993; Bhattacharya \& Medlin, 1995; Saunders et al., 1995, 1997; Cavalier-Smith et al., 1995; Cavalier-Smith \& Chao, 1996; Van de Peer et al., 1996b), although classifications have been based upon ultrastructural and biochemical observations (Andersen, 1991; Williams, 1991a, b). Furthemore, it seems that the heterokont algae, as a group, are most closely related to certain heterotrophic phyla such as oomycetes and hyphochytriomycetes (Forster et al.,
1990; Bhattacharya et al., 1991, 1992; Cavalier-Smith et al., 1994b; Leipe et al., 1994, 1996; Van der Auwera et al., 1995) and form together the Heterokonta (Cavalier-Smith et al., 1994b) or the stramenopiles (Patterson, 1989). Finally, the dinoflagellates are unicellular biflagellated organisms that are a sister group of the apicomplexans, while both of them form, together with the ciliates, a monophyletic group called the alveolates (Gajadhar et al., 1991; Patterson \& Sogin, 1993; Van de Peer \& De Wachter, 1997a).

Beside these four main groups of algae, a few smaller groups of algae exist. One of these is the chlorarachniophytes, an intriguing group of marine, unicellular amoeboflagellate algae showing a possible common ancestry with filose amoebae (Bhattacharya et al., 1995b; Van de Peer et al., 1996a). Together with the cryptophytes, haptophytes and heterokont algae, the chlorarachniophytes contain plastids surrounded by four membranes, and are believed to have acquired these by engulfing another eukaryotic plastid-containing algae (secondary endosymbiosis; Gibbs, 1981; Douglas et al., 1991; Maier et al., 1991; CavalierSmith, 1993, 1995; Whatley, 1993; Martin et al., 1998; Palmer \& Delwiche, 1998; Delwiche, 1999). Chlorarachniophytes and cryptophytes still contain a small nucleus-like structure called the nucleomorph (NM) 
(Ludwig \& Gibbs, 1989; Gibbs, 1993; McFadden, 1993), situated between the two inner and the two outer membranes surrounding the plastid and which is a remnant of the endosymbiont's nucleus. Since the NM of cryptomonads and chlorarachniophytes still encode 18S rRNA, it could be demonstrated that the endosymbionts of chlorarachniophytes are probably related to green algae, while those of cryptomonads are most probably related to red algae (Van de Peer et al., 1996a). Although the latter relationship is usually not supported by bootstrap analysis, it has been suggested previously on the basis of SSU rRNA (Douglas et al., 1991; Maier et al., 1991; Maerz et al., 1992). In haptophytes and heterokont algae, a remnant of the endosymbionts nucleus does not exist anymore and therefore the true nature of the endosymbiont that gave rise to their plastids can only be inferred through sequence analysis of plastid genes. Dinoflagellates have plastids that are surrounded by three membranes. As recently demonstrated, the DNA organization of these plastids differs radically from all other plastid genomes. Dinoflagellate plastids have a unique genome organization in which each gene is located on its own minicircular chromosome (Zhang et al., 1999). A brief summary of the different algal taxa, classified on the basis of their main pigments and the number of membranes surrounding the plastids, is shown in Table 1.

In this paper, we have focused on (1) the phylogenetic position and relationships of the different groups of algae discussed above and on (2) the phylogenetic relationships between different taxa that belong to the heterokont algae. Regarding the latter, Saunders et al. (1995, 1997) and Potter et al. (1997) suggested, by combining ultrastructural, biochemical and SSU rRNA sequence data, that all heterokont algae with a highly reduced flagellar apparatus such as bacillariophytes (diatoms), pelagophytes, and dictyochophytes, form a monophyletic group. However, in other analyses on the basis of the SSU rRNA (Van de Peer et al., 1996b, 2000a; Leipe et al., 1996) and on the basis of $r b c L$ data (Daugbjerg \& Andersen, 1997b) such a monophyly is not supported. Overall, despite several studies, the deeper branching relationships within the heterokont algae remain unclear and need further investigation.

In order to address the questions raised above, we determined the complete, or nearly complete, largesubunit rRNA (LSU rRNA) sequence of the bacillariophytes (diatoms) Cylindrotheca closterium and Rhizosolenia setigera; the dictyochophyceae Apedinella radians, Dictyocha speculum and Rhizochromulina cf. marina; the pelagophyceae Aureococcus anophagefferens and Pelagomonas calceolata; the haptophyte Prymnesium patelliferum and Phaeocystis antarctica; the cryptophyte Guillardia theta (nuclear gene); and the chlorarachniophyte Chlorarachnion strain CCMP621' (nuclear gene). Phylogenetic trees were constructed with different methods and on the basis of
LSU rRNA as well as on concatenated sequence alignments of LSU and SSU rRNA.

\section{METHODS}

Sequence determination. The LSU rDNA of all species was amplified by PCR, either in one or several overlapping fragments. The primer combinations that were used for these PCRs are listed in Table 2, and their location is indicated relative to the $18 \mathrm{~S}$ and $28 \mathrm{~S}$ rDNA gene sequences from Saccharomyces cerevisiae (Van der Auwera et al., 1994, 1995). All reactions were performed in $50 \mu$ containing $200 \mu \mathrm{M}$ of each $\mathrm{dNTP}, 0.5 \mu \mathrm{M}$ of each primer and 0.025 $\mathrm{U} / \mu \mathrm{l}$ Taq DNA polymerase in the appropriate buffer (Roche Diagnostics). Thirty cycles were performed, each consisting of a denaturation step of $1 \mathrm{~min}$ at $94{ }^{\circ} \mathrm{C}$, an annealing step of $1 \mathrm{~min}$ at various temperatures, and an annealing step at $72{ }^{\circ} \mathrm{C}$ for different amounts of time. The exact annealing temperature and extension time of each reaction is listed in Table 2 . The cycling was always preceded by a denaturation step of 2 min at $94{ }^{\circ} \mathrm{C}$ and followed by an extension step of $10 \mathrm{~min}$ at $72{ }^{\circ} \mathrm{C}$.

The LSU rDNA of the chlorarachniophyte strain CCMP 621 was amplified in two overlapping fragments (Table 2). Because the template contained nuclear as well as NM DNA, each PCR product was probably a mixture of two amplicons. As only one amplification product was observed in each reaction, they could not be separated on the basis of their length. However, since the NM sequence had already been determined (Gilson \& McFadden, 1996), it was possible to digest each amplicon with a panel of restriction enzymes that were known to cut the NM fragment. Enzymes that only cut the NM fragment could be readily identified since they generate the restriction fragments characteristic of the $\mathrm{NM}$, while leaving the nuclear PCR product intact. It was observed that digestion of the second PCR fragment did not result in the expected NM fragments. Since it is our experience that the antisense primer used to generate this fragment is unsuccessful in many amplifications, it was assumed that this primer worked well on the nuclear DNA, while the NM DNA was selected against because too many mismatches were present. As a result no further steps were needed to obtain the pure second nuclear DNA fragment. In order to obtain the first pure nuclear amplification product, total genomic DNA was digested with the restriction enzyme PstI, which was shown to cut only the NM DNA between both primer annealing sites used in the PCR. When the digested DNA was used as template, only the nuclear genome was amplified, while the NM DNA was not intact and therefore could not be amplified.

The LSU rDNA of Guillardia theta was amplified in one fragment covering the $28 \mathrm{~S}$ rDNA (Table 2). The amplification of the fragment covering 5.8S rDNA $( \pm 162$ nucleotides) and the $5^{\prime}$ end of the 28S rDNA $( \pm 40$ nucleotides) was unsuccessful and as a result these sequences were not determined. As in the case of the chlorarachniophyte CCMP621, the PCR product was probably again a mixture of nuclear and NM DNA. In order to obtain pure nuclear DNA, the same approach was followed, using BamHI to cut the NM DNA between both primer annealing sites used in the PCR. 
Table 2. Amplified PCR fragments

\begin{tabular}{|c|c|c|c|c|}
\hline \multirow[t]{2}{*}{ Organism* } & \multicolumn{4}{|c|}{ PCR conditions $\dagger$} \\
\hline & Sense primer & Antisense primer & Extension (min) & Annealing $\left({ }^{\circ} \mathrm{C}\right)$ \\
\hline ССМР621 & $\begin{array}{l}1624-1643(18 S) \\
1252-1274(28 S)\end{array}$ & $\begin{array}{l}1940-1917(28 S) \\
3378-3357(28 S)\end{array}$ & $\begin{array}{l}3 \\
3\end{array}$ & $\begin{array}{l}55 \\
55\end{array}$ \\
\hline Guillardia theta & $26-46(28 S)$ & $3378-3357(28 \mathrm{~S})$ & 4 & 50 \\
\hline $\begin{array}{l}\text { Prymnesium patelliferum } \\
\text { Phaeocystis antarctica } \\
\text { Aureococcus anophagefferens } \\
\text { Pelagomonas calceolata } \\
\text { Apedinella radians } \\
\text { Dictyocha speculum }\end{array}$ & $\begin{array}{c}1624-1643(18 \mathrm{~S}) \\
26-46(28 \mathrm{~S}) \\
1917-1940(28 \mathrm{~S})\end{array}$ & $\begin{array}{c}660-636(28 \mathrm{~S}) \\
2210-2185(28 \mathrm{~S}) \\
3378-3357(28 \mathrm{~S})\end{array}$ & $\begin{array}{l}2 \\
2 \\
2\end{array}$ & $\begin{array}{l}55 \\
55 \\
55\end{array}$ \\
\hline Rhizochromullna cf. marina & $\begin{array}{c}1624-1643(18 S) \\
26-46(28 S) \\
1252-1274(28 S)\end{array}$ & $\begin{array}{c}660-636(28 \mathrm{~S}) \\
2210-2185(28 \mathrm{~S}) \\
3126-3106(28 \mathrm{~S})\end{array}$ & $\begin{array}{l}2 \\
2 \\
2\end{array}$ & $\begin{array}{l}55 \\
55 \\
55\end{array}$ \\
\hline $\begin{array}{l}\text { Cylindrotheca closterium } \\
\text { Rhizosolenia setigera }\end{array}$ & $\begin{array}{c}1624-1643(18 \mathrm{~S}) \\
26-46(28 \mathrm{~S}) \\
1252-1274(28 \mathrm{~S}) \\
1917-1940(28 \mathrm{~S})\end{array}$ & $\begin{array}{c}660-636(28 \mathrm{~S}) \\
1858-1841(28 \mathrm{~S}) \\
2413-2393(28 \mathrm{~S}) \\
3378-3357(28 \mathrm{~S})\end{array}$ & $\begin{array}{l}2 \\
2 \\
2 \\
2\end{array}$ & $\begin{array}{l}59 \\
54 \\
59 \\
57\end{array}$ \\
\hline
\end{tabular}

* The LSU rDNA of all species listed in the same row (separated by the horizontal lines) were amplified using the same fragments and conditions.

$\dagger$ Each line represents a different PCR reaction, indicating the annealing temperature, extension time and primers used. The position of the primers is given relative to the $18 \mathrm{~S}$ or $28 \mathrm{~S}$ rDNA genes of $S$. cerevisiae (in parentheses).

The LSU rDNAs of Aureococcus anophagefferens, Pelagomonas calceolata, Apedinella radians, Dictyocha speculum, Rhizochromulina cf. marina and both haptophytes, viz. Prymnesium patelliferum and Phaeocystis antarctica, were amplified in three overlapping PCR fragments, while four amplicons were needed to cover the Cylindrotheca closterium and Rhizosolenia setigera genes (Table 2).

The PCR amplified fragments were purified with the QIAquick PCR purification kit (Qiagen) and then used as template for an asymmetric PCR, using the same conditions as for the PCR but omitting one of the primers. The asymmetric PCR products were again purified with the QIAquick PCR purification kit and used as template for cycle sequencing reactions. This procedure is a modification of the one of Allard et al. (1991).

Sequencing reactions were performed with Cy5-labelled primers and the Thermo sequenase fluorescent-labelled primer cycle sequencing kit from Amersham Pharmacia Biotech according to the manufacturer's instructions. Reactions were analysed on an ALF express automatic DNA sequencer (Amersham Pharmacia Biotech). For sequencing, the primers published in Van der Auwera et al. (1994, 1995, 1997) were used, and one new primer was synthesized which anneals at position 46-26 in the Saccharomyces cerevisiae 28S rRNA gene and has the sequence ATATGCTTAARTTCAGCGGGT. The 5.8S and 28S rDNA were sequenced completely, except for 5.8S rDNA and about 40 nucleotides at the $5^{\prime}$ end of the $28 \mathrm{~S}$ rDNA of Guillardia theta. Also about 40 nucleotides at the $3^{\prime}$ end of the $28 \mathrm{~S}$ rDNA of all the species were not determined because they could not be amplified by PCR due to the lack of a suitable primer beyond the $3^{\prime}$ end of the gene, as was also the case for about 80 nucleotides at the $5^{\prime}$ end of 5.8S rDNA and about 250 nucleotides at the $3^{\prime}$ end of the $28 \mathrm{~S}$ rDNA from Rhizochromulina cf. marina. Sequencing was done on both strands, except for about 50 nucleotides at both ends of the 5.8S rDNA and the $5^{\prime}$ end of the 28S rDNA for CCMP621, Phaeocystis antarctica, Rhizochromulina cf. marina and Aureococcus anophagefferens, which were sequenced on one strand only. When several PCR products were used to cover the entire gene, the overlapping regions were sequenced to make sure that all products are from the same template.

Sequence alignment and tree construction. The LSU rRNAs determined in this study (accession numbers can be found in Table 3) were added to the European LSU rRNA sequence database (De Rijk et al., 2000). Sequences were aligned with the DCSE sequence editor (De Rijk \& De Wachter, 1993), taking into account both primary and secondary structure information. Neighbour-joining (Saitou \& Nei, 1987) trees based on Kimura (1980) and substitution rate calibrated (SRC) distances taking into account among-site rate variation (Van de Peer et al., 1996b) were constructed and drawn with TREECON for Windows (Van de Peer \& De Wachter, 1997b). Bootstrapped maximum-parsimony trees were constructed with PAUP* (Swofford, 1998). Maximum-likelihood trees were inferred by the PUZZLE program (Strimmer \& von Haeseler, 1996). Secondary structure models were drawn with the software RNAViz (De Rijk \& De Wachter, 1997), a versatile program developed to draw secondary structures of molecules in a fast and user-friendly way. 
Table 3. Lengths and accession numbers of the $5.8 \mathrm{~S}$ and $28 \mathrm{~S}$ rDNA sequences (only the length of the determined part is given)

\begin{tabular}{|lccc|}
\hline Organism & Molecule & Length (bp) & Accession number \\
\hline Chlorarachnion sp. CCMP621 & $5.8 \mathrm{~S}$ & 163 & AF289035 \\
Guillardia theta & $28 \mathrm{~S}$ & 3296 & AF289036 \\
Prymnesium patelliferum & $5.8 \mathrm{~S}$ & - & - \\
& $28 \mathrm{~S}$ & 3324 & AF289037 \\
Phaeocystis antarctica & $5.8 \mathrm{~S}$ & 162 & AF289038 \\
& $28 \mathrm{~S}$ & 3204 & AF289038 \\
Aureococcus anophagefferens & $5.8 \mathrm{~S}$ & 162 & AF289039 \\
& $28 \mathrm{~S}$ & 3267 & AF289040 \\
Rhizochromulina cf. marina & $5.8 \mathrm{~S}$ & 162 & AF289041 \\
Apedinella radians & $28 \mathrm{~S}$ & 3272 & AF289042 \\
Dictyocha speculum & $5.8 \mathrm{~S}$ & 84 & AF289043 \\
Pelagomonas calceolata & $28 \mathrm{~S}$ & 3083 & AF289044 \\
& $5.8 \mathrm{~S}$ & 162 & AF289045 \\
Rhizosolenia setigera & $28 \mathrm{~S}$ & 3226 & AF289046 \\
Cylindrotheca closterium & $5.8 \mathrm{~S}$ & 162 & AF289046 \\
& $28 \mathrm{~S}$ & 3251 & AF289047 \\
& $5.8 \mathrm{~S}$ & 162 & AF289047 \\
& $28 \mathrm{~S}$ & 3269 & AF289048 \\
& $5.8 \mathrm{~S}$ & 162 & AF289048 \\
& $28 \mathrm{~S}$ & 3331 & AF289049 \\
& $5.8 \mathrm{~S}$ & 162 & \\
\hline
\end{tabular}

\section{RESULTS AND DISCUSSION}

For all species, approximately 40 bases at the $3^{\prime}$ end of the $28 \mathrm{~S}$ rDNA were not determined, because these were not amplified in the PCR reactions due to the lack of a primer downstream of the $3^{\prime}$ end. Apart from that, complete $5.8 \mathrm{~S}$ and $28 \mathrm{~S}$ rDNA sequences from the chlorarachniophyte Chlorarachnion strain CCMP621 (host), the haptophytes Prymnesium patelliferum and Phaeocystis antarctica, the bacillariophytes Cylindrotheca closterium and Rhizosolenia setigera, the dictyochophytes Apedinella radians, Dictyocha speculum and Rhizochromulina cf. marina, and the pelagophytes Aureococcus anophagefferens and Pelagomonas calceolata were determined. For the cryptophyte Guillardia theta (nuclear gene), the complete LSU rDNA was determined except for the 5.8S rDNA and about 40 nucleotides at the $5^{\prime}$ end of the $28 \mathrm{~S}$ rDNA. The LSU rRNA sequence from Rhizochromulina cf. marina was determined except for about 80 nucleotides at the $5^{\prime}$ end of the 5.8S rDNA and about 250 nucleotides at the $3^{\prime}$ end of the 28S rDNA. The lengths of the sequences and their accession numbers are given in Table 3.

\section{Phylogenetic position of the algal taxa}

Fig. 1 shows a neighbour-joining tree considering among-site rate variation and based on 85 LSU rRNA sequences of different eukaryotes belonging to the socalled crown taxa (Knoll, 1992; Van de Peer et al., 2000a). Estimation of nucleotide substitution rates and estimation of evolutionary distances taking into account the specific distribution of substitution rates (Van de Peer et al., 1996b) was based on the complete LSU rRNA, except for the variable regions of the molecule for which alignment was problematic indicated in Fig. 5 (see also De Rijk et al., 2000). As can be seen in Fig. 1, several well-supported monophyletic groups can be discerned: viz. the animals, red algae, land plants plus green algae, fungi, stramenopiles and alveolates. Stramenopiles and alveolates appear as sister groups, albeit not supported by bootstrap analysis (bootstrap support, BS, $56 \%$ ). Nevertheless, a sister relationship of alveolates and stramenopiles or heterokonts has been suggested before on the basis of SSU rRNA, although also never statistically supported (Saunders et al., 1995; Van de Peer \& De Wachter, 1997a). The chlorarachniophytes, cryptophytes and haptophytes seem to form independent lineages, not specifically related to any of the other eukaryotic taxa. Also this finding is in good agreement with SSU rRNA data published previously (Van de Peer \& De Wachter, 1997a; Van de Peer et al., 2000a). Interesting to note is that a close relationship between fungi and animals is hardly ever supported by LSU rRNA data (Fig. 1; Van der Auwera et al., 1998; Van de Peer et al., 2000b), although this clade is firmly established by SSU rRNA analyses (Wainright et al., 1993; Van de Peer \& De Wachter, 1997a; Van de Peer et al., 2000a), by their unique possession of a large insertion in protein synthesis elongation factor- $1 \alpha$ (EF- $1 \alpha$; Baldauf \& Palmer, 1993), and by analyses of the conservative, 


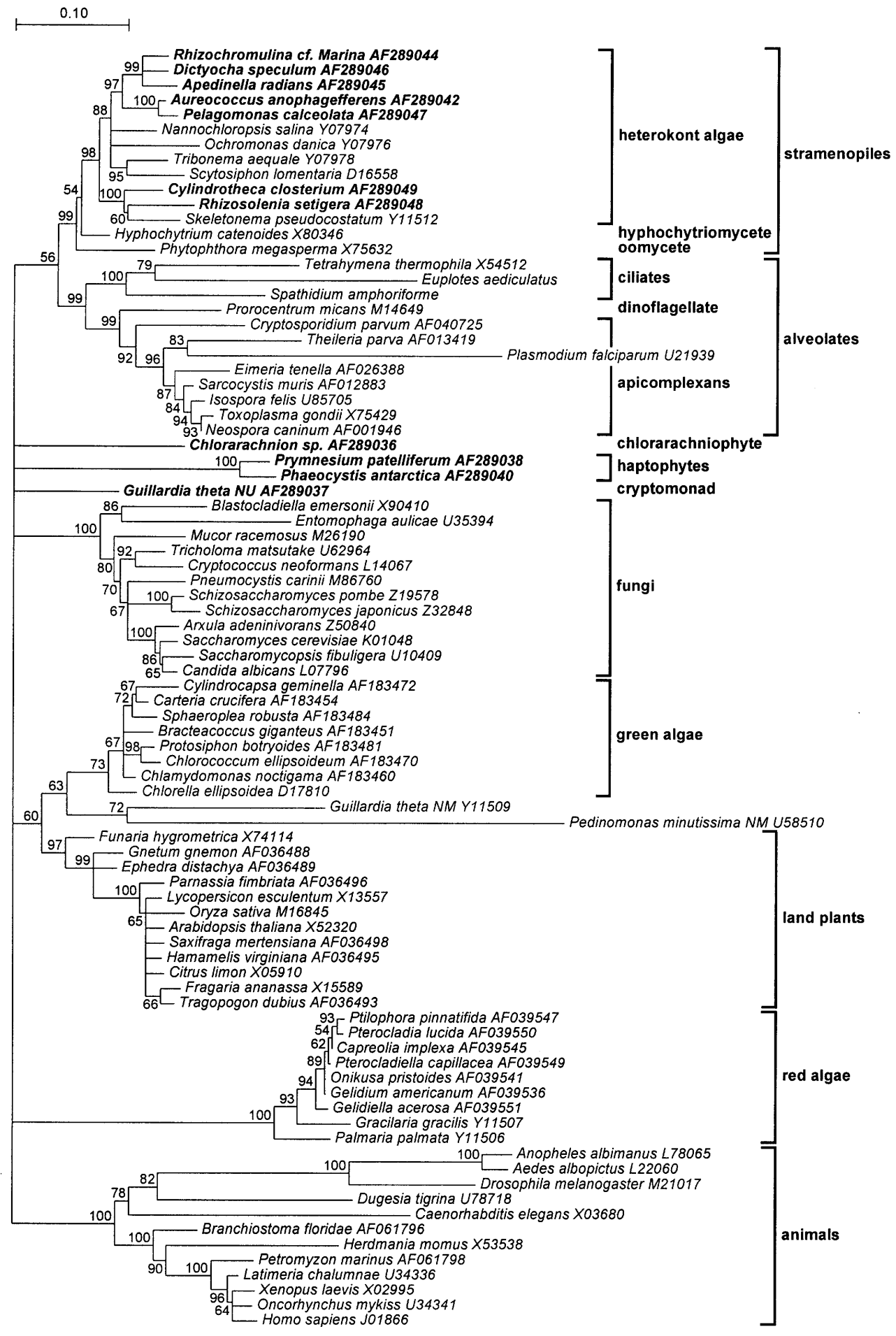

Fig. 1. Unrooted evolutionary tree of 85 eukaryotic LSU rRNA sequences constructed by neighbour-joining from a distance matrix based on substitution rate calibration (Van de Peer et al., 1996b). Algae for which the sequence was determined in this study are in bold. The evolutionary distance between two organisms is obtained by summing the lengths of the connecting branches along the horizontal axis, using the scale on top. Bootstrap values (Felsenstein, 1985) above $50 \%$ (out of 500 resamplings) are shown at the internodes. Branches supported by less than $50 \%$ are drawn as unresolved. Taxon designations are placed to the right of the corresponding clusters. 


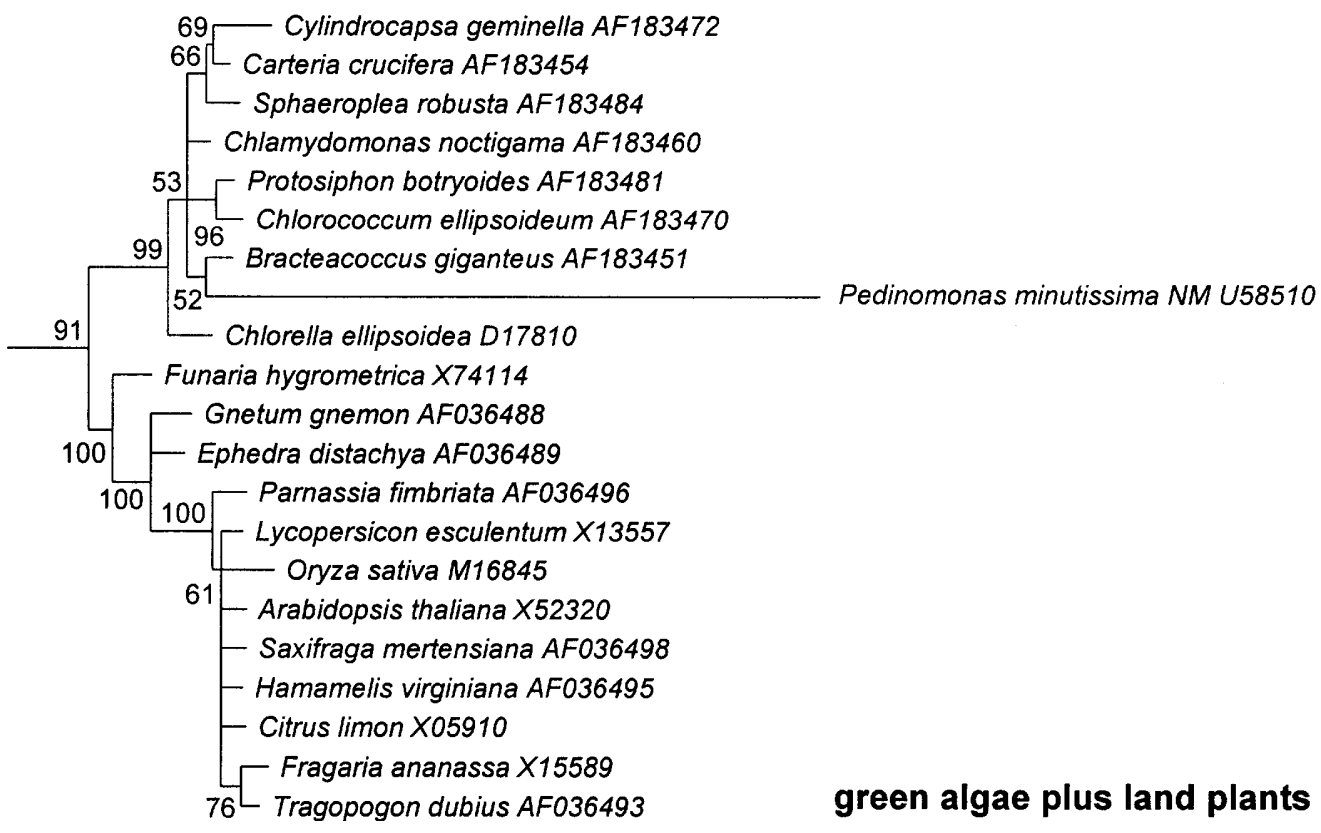

Fig. 2. Detail of the tree topology and bootstrap support for the green algae plus land plants but with removal of the NM sequence of the cryptomonad Guillardia theta (Fig. 1). See text for details.

taxonomically well-sampled proteins $\alpha$-tubulin, $\beta$ tubulin, EF- $1 \alpha$ and actin (Baldauf, 1999).

In the tree of Fig. 1, the NM LSU rRNA of the chlorarachniophyte Pedinomonas is clustered with the LSU rRNA of the cryptomonad NM Guillardia, although their genomes are most probably unrelated (Van de Peer et al., 1996b). Although this clustering is thus unexpected it has been noticed before on the basis of SSU rRNA (Cavalier-Smith et al., 1994a; Van de Peer et al., 1996b; Van de Peer \& De Wachter, 1997a). However, this attraction appears to be artifactual and caused by the increased evolutionary rate of the NM rRNAs, although SRC is applied to reduce longbranch attraction artifacts (Van de Peer et al., 1996a). The strong attraction of the cryptomonad NM sequence by the chlorarachniophyte NM can be demonstrated by omitting the latter from the analysis. When the chlorarachniophyte NM is omitted from the analysis and only the cryptomonad NM is included (not shown), it forms an independent lineage, clearly separated from the green algae and land plants, which still form a very well-supported clade. However, on the basis of LSU rRNA, the red algal ancestry of the cryptomonad endosymbiont, as suggested previously (Douglas et al., 1991; Maier et al., 1991; Maerz et al., 1992; Van de Peer et al., 1996a) cannot be demonstrated. When only the chlorarachniophyte NM sequence is included, its phylogenetic position remains basically unchanged, but the bootstrap support for the clade formed by green algae plus land plants increases spectacularly (Fig. 2). The strong artificial attraction between the NM rRNAs remains embarrassing but possibly might be explained by co-variation (Van de Peer, unpublished) or convergence in their sequences due to similar evolutionary pressure after becoming endosymbionts (Ishida et al., 1999).

Maximum-parsimony analysis (not shown) shows the same overall tree topology as that found on the basis of distance analysis and the same major clusters are recognized. The divergence order between the different major clusters is largely unresolved, except that stramenopiles and alveolates are found as sister groups, but again not supported by bootstrap analysis (bootstrap proportion, BP, $51 \%$ ). Contrary to the distance tree shown in Fig. 1, the NM sequences form a monophyletic (BS $84 \%$ ) but independent lineage and thus do not group with the green algae. Furthermore, even when the NM sequence of the cryptomonad Guillardia is omitted from the analysis, the NM sequence of Pedinomonas does not share a common ancestry with the green algae, although this is highly supported in distance analysis (BS 99\%), at least when among-site rate variation is taken into account. If this is not the case, also in distance trees the NM sequence of Pedinomonas forms an independent evolutionary lineage (not shown).

As can be seen in Fig. 1, many of the deeper divergences in the eukaryotic crown are unresolved. Actually, the resolution for deeper divergences within the LSU rRNA tree seems to be less robust than in SSU rRNA trees, where one usually finds a close and statistically well-supported relationship between animals and fungi, and between stramenopiles and alveolates (e.g. 


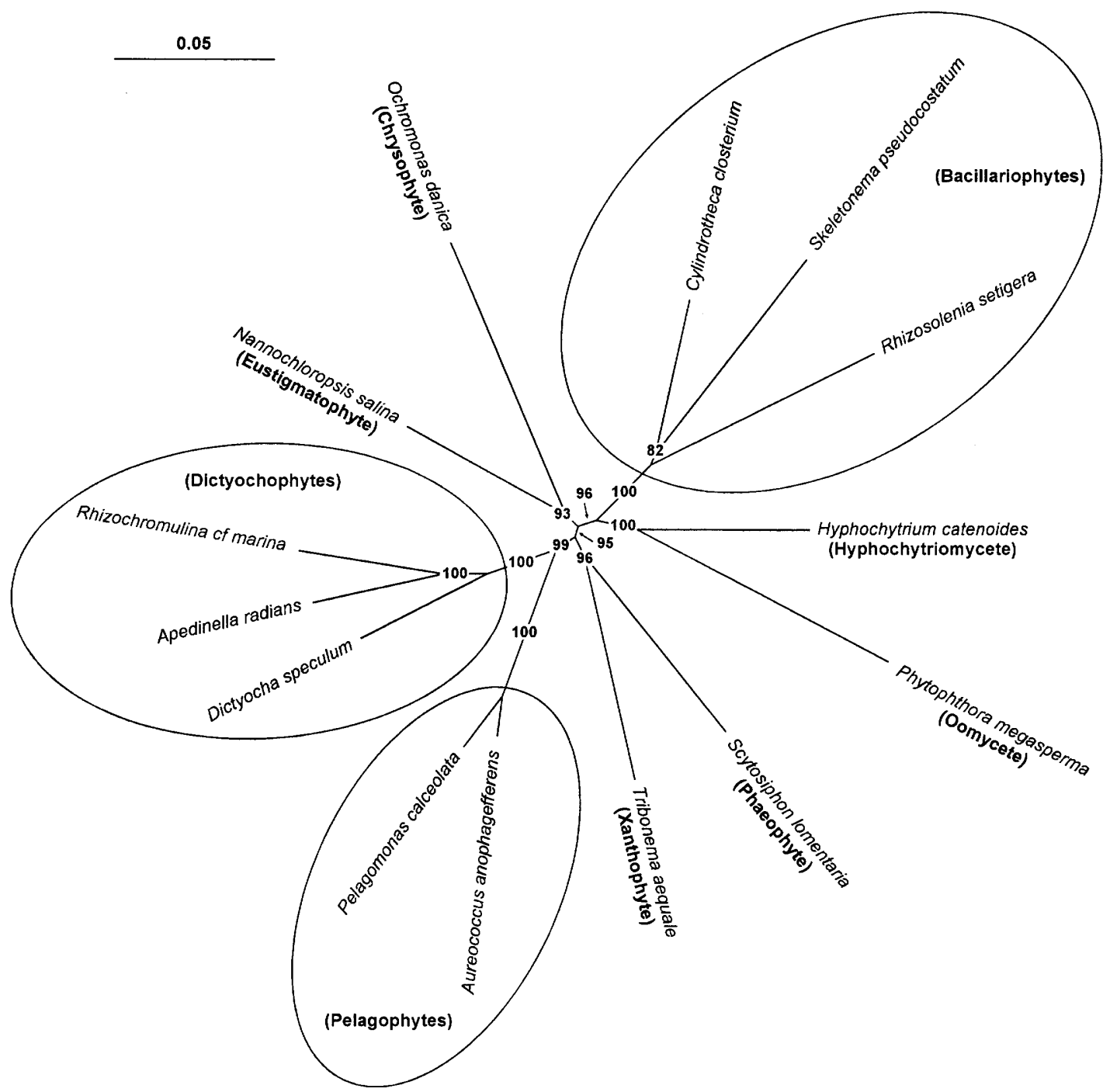

Fig. 3. Unrooted phylogenetic tree for the Heterokonta based on a concatenated alignment of SSU and LSU rRNA sequences.

Van de Peer \& De Wachter, 1997a). On the other hand, in some cases the LSU rRNA seems to be more informative than the SSU rRNA. On the basis of LSU rRNA the common ancestry of Fungi and Microsporidia, the latter of which are amitochondrial parasites previously thought to be the descendants of a primitive, ancient eukaryotic lineage (Vossbrinck et al., 1987), could be confirmed (Van de Peer et al., 2000b). Although this relationship has been supported by protein-coding genes such as tubulin, RNA polymerase, and others (Keeling \& Doolittle, 1996; Hirt et al., 1999), such a common origin cannot be confirmed on the basis of SSU rRNA (Philippe \& Germot, 2000; Philippe et al., 2000; unpublished results). This again demonstrates that, despite considerable debate on the vices and virtues of various molecular phylogenetic markers, all have their strengths and weaknesses.

Nevertheless, it has been recently demonstrated that the branching order between many deep divergences can possibly be resolved by combining several molecular markers (Moreira et al., 2000; Baldauf et al., 2000). Therefore, in order to find out whether the small or scarcely sampled algal taxa such as the chlorarachniophytes, cryptomonads and haptophytes are important missing links among major clades, it would be highly interesting to determine the sequences of some protein-coding genes for these organisms.

\section{Phylogenetic relationships within the heterokont algae}

On the basis of the SSU rRNA, the phylogenetic relationships between the different taxa that belong to the so-called heterokont algae cannot be deduced unequivocally (Ariztia et al., 1991; Andersen et al., 1993, 1998, 1999; Potter et al., 1997; Lavau et al., 


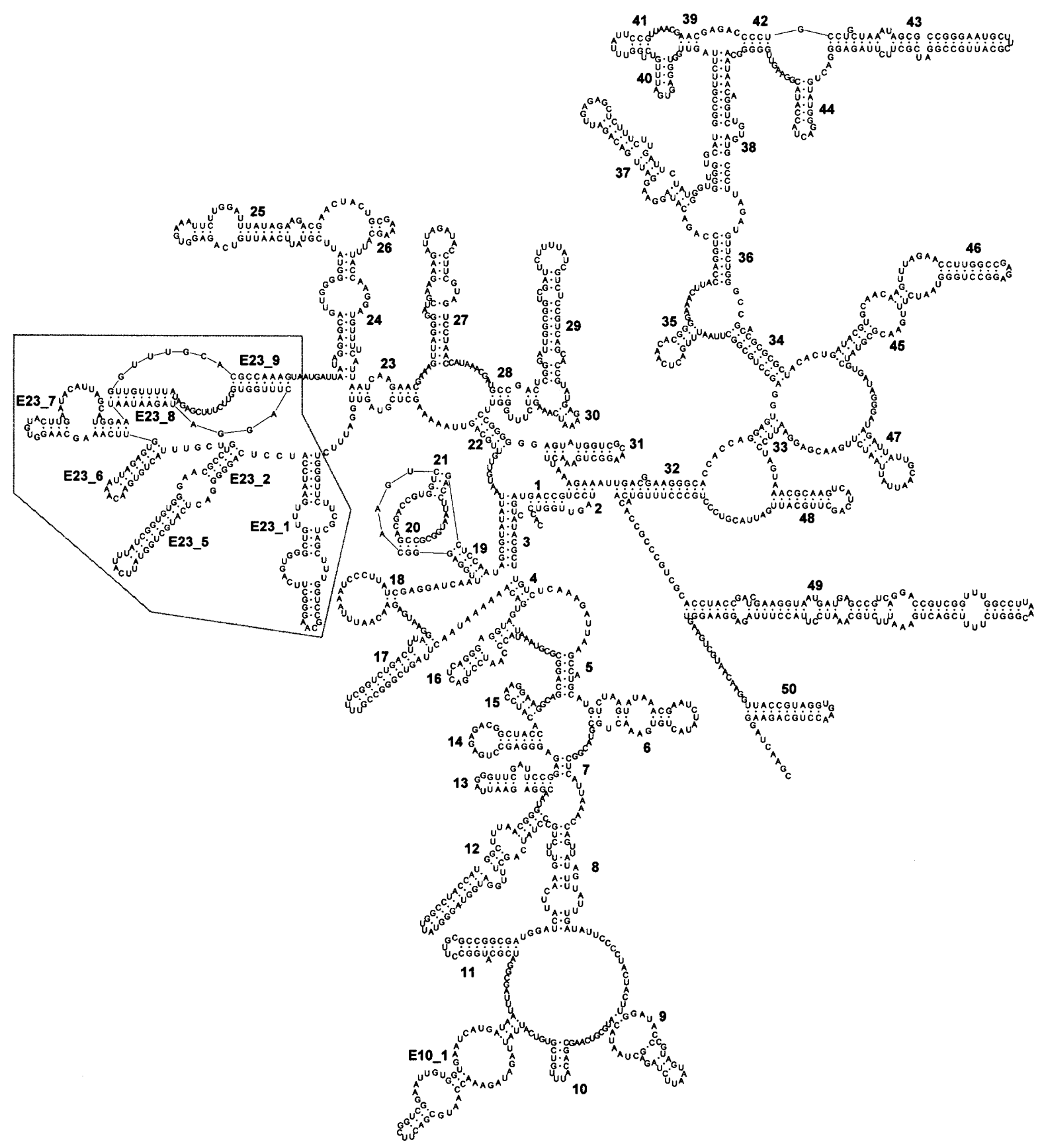

Fig. 4. Secondary structure model of the SSU rRNA of the dictyochophyte Apedinella radians. The hypervariable region E23, indicated by a box, was omitted from the alignment.

1997; Saunders et al., 1995, 1997; Bailey et al., 1998; Van de Peer \& De Wachter, 1997a; Van de Peer et al., 2000a). Therefore, we determined the complete or nearly complete LSU rRNA sequences of several species for which the SSU rRNA sequence was already known. Fig. 3 shows an unrooted phylogenetic tree of the Heterokonta (heterokont algae plus oomycetes, and hyphochytriomycetes) based on the concatenation of SSU rRNA and LSU rRNA sequences. The complete SSU rRNA sequence was used, except for the hypervariable region E23 (see Fig. 4), while three hypervariable regions of the LSU rRNA were omitted (see Fig. 5). Since sequence dissimilarities between heterokonts are rather small, evolutionary distances were estimated according to Kimura (1980). As expected, other distance estimates gave the same tree topology.

In the combined analysis, the clustering of the dictyochophytes and the pelagophytes, as already suggested 


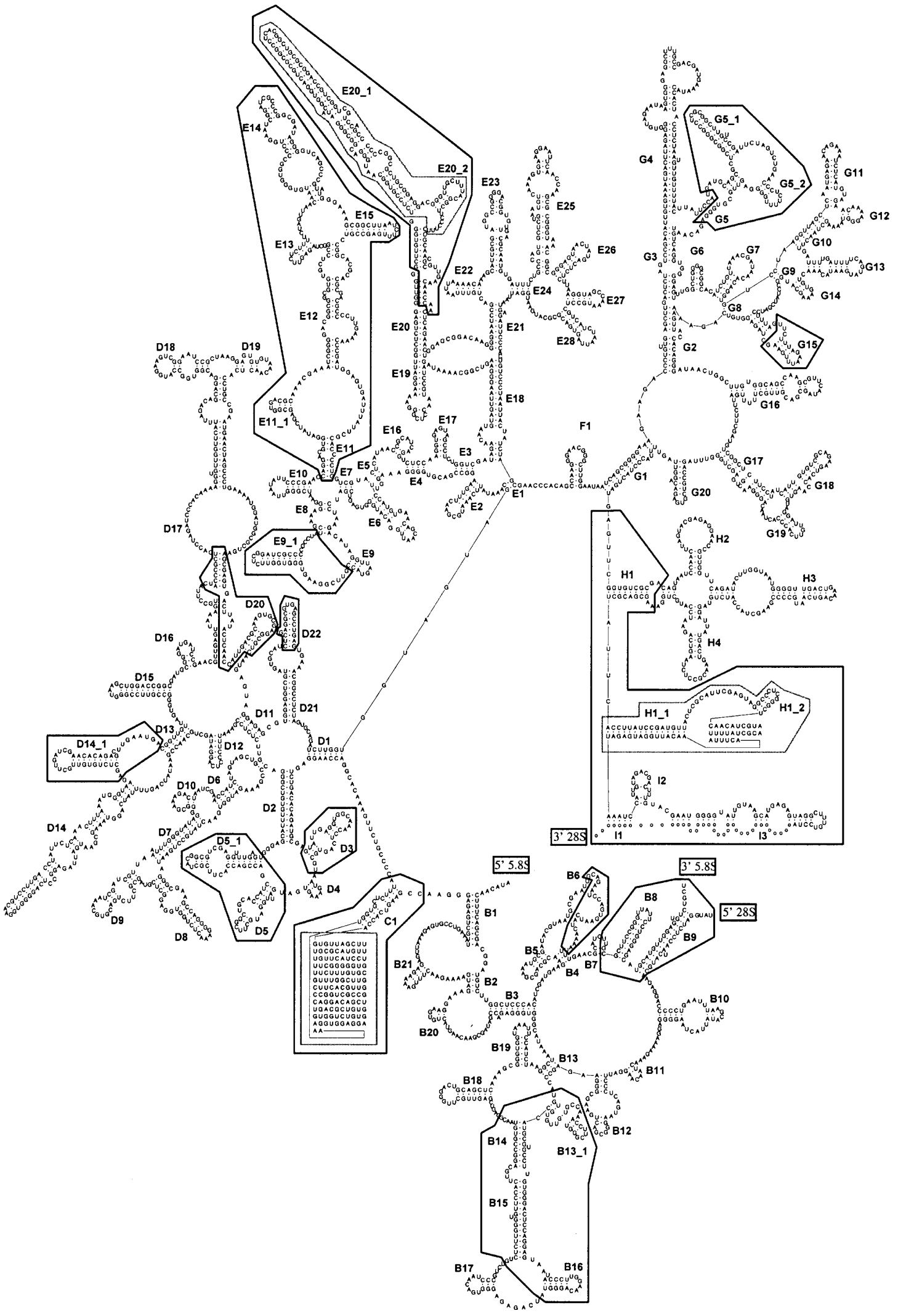

Fig. 5. Secondary structure model of the LSU rRNA of the dictyochophyte Apedinella radians. For the construction of the LSU tree of Fig. 1 all the regions indicated in black boxes were omitted. For the construction of the tree based on the concatenated alignment of SSU rRNA and LSU rRNA sequences of Heterokonta (Fig. 2), only the hypervariable regions indicated in grey boxes were omitted. 
on the basis of SSU rRNA (Saunders et al., 1995; Van de Peer \& De Wachter, 1997a) and LSU rRNA alone (Fig. 1), is confirmed: both groups share a common ancestry highly supported by bootstrap analysis (BP $99 \%$ ). The close relationship between xanthophytes and phaeophytes, as previously suggested on the basis of rRNA data (Ariztia et al., 1991; Bhattacharya et al., 1992; Leipe et al., 1994; Saunders et al., 1995; Potter et al., 1997; Van de Peer \& De Wachter, 1997a; Van der Auwera et al., 1997) is also confirmed (BP 96\%). On the basis of the concatenated sequence alignment, also the chysophytes (represented here solely by Ochromonas danica) and the eustigmatophytes (here represented by Nannochloropsis salina) seem to be sister taxa, highly supported by bootstrap analysis. This sister group relationship could not be demonstrated when SSU rRNA or LSU rRNA sequences were analysed separately (Van de Peer \& De Wachter, 1997a; Fig. 1). Furthermore, it should be pointed out that this sister-group relationship only holds when neither the chrysophytes nor the eustigmatophytes form the first diverging lineage within the Heterokonta. Although on the basis of SSU rRNA this cannot be ruled out (Van de Peer \& De Wachter, 1997a; Van de Peer et al., 2000a), this seems to be unlikely on the basis of LSU rRNA (see Fig. 1), where the heterokont fungi form the first diverging lineages. If this is indeed true, the heterokont algae form a wellsupported monophyletic lineage (BP $100 \%$ ), of which the bacillariophytes form the first diverging taxon. Contrary to what has been previously suggested, the bacillariophytes do not form a monophyletic cluster with the pelagophytes and dictyochophytes, although they do share the possession of a reduced flagellar apparatus (Saunders et al., 1995). Maximum-likelihood analysis (not shown) shows the same topology and similar support as the tree in Fig. 3. Maximumparsimony supports all the sister-relationships discussed above, but support is lacking for any of the relationships between classes of heterokont algae at a deeper level.

\section{ACKNOWLEDGEMENTS}

Y.V.d.P. acknowledges the support of the University of Antwerp (Belgium) and the University of Konstanz (Germany, Professor Axel Meyer). The authors thank Geoff McFadden for DNA from the chlorarachniophyte strain CCMP621, Uwe G. Maier for DNA from Guillardia theta, Linda Medlin for DNA from Prymnesium patelliferum and Phaeocystis antarctica and Robert A. Andersen for DNA from the different heterokont algae discussed in this paper. Y.V.d.P. and G.V.d.A. are Research Fellows of the National Fund for Scientific Research - Flanders (Belgium).

\section{REFERENCES}

Allard, M. W., Ellsworth, D. L. \& Honeycutt, R. L. (1991). The production of single-stranded DNA suitable for sequencing using the polymerase chain reaction. Biotechniques 10, 24-26.

Andersen, R. A. (1987). The Synurophyceae classis nova: a new class of algae. Am J Bot 74, 337-353.
Andersen, R. A. (1991). The cytoskeleton of chromophyte algae. Protoplasma 164, 143-159.

Andersen, R. A., Saunders, G. W., Paskind, M. P. \& Sexton, J. P. (1993). Ultrastructure and 18S rRNA gene sequence for Pelagomonas calceolata gen. et sp. nov. and the description of a new algal class, the Pelagophyceae classis nov. J Phycol 29, 701-715.

Andersen, R. A., Brett, R. W., Potter, D. \& Sexton, J. P. (1998). Phylogeny of the Eustigmatophyceae based upon the 18S rRNA gene, with emphasis on Nannochloropsis. Protist 149, 61-74.

Andersen, R. A., Van de Peer, Y., Potter, D., Sexton, J. P., Kawachi, M. \& LaJeunesse, T. (1999). Phylogenetic analysis of the SSU rDNA from members of the Chrysophyceae. Protists 150, 71-84.

Ariztia, E. V., Andersen, R. A. \& Sogin, M. L. (1991). A new phylogeny for chromophyte algae using 16S-like rRNA sequences from Mallomonas papillosa (Synurophyceae) and Tribonema aequale (Xanthophyceae). J Phycol 27, 428-436.

Bailey, J. C., Bidigare, R. R., Christensen, S. J. \& Andersen, R. A. (1998). Phaeothamniophyceae classis nova: a new lineage of chromophytes based upon photosynthetic pigments, rbcL sequence analysis and ultrastructure. Protist 149, 245-263.

Baldauf, S. L. (1999). A search for the origins of animals and fungi, comparing and combining molecular data. Am Nat 154, S178-S188.

Baldauf, S. L. \& Palmer, J. D. (1993). Animals and fungi are each other's closest relatives: congruent evidence from multiple proteins. Proc Natl Acad Sci US A 90, 11558-11562.

Baldauf, S. L., Roger, A. J., Wenk-Siefert, I. \& Doolittle, W. F. (2000). A kingdom level phylogeny of eukaryotes based on combined protein data. Science $\mathbf{2 9 0}$, 972-977.

Bhattacharya, D. \& Medlin, L. (1995). The phylogeny of plastids: a review based on comparisons of small-subunit ribosomal RNA coding regions. $J$ Phycol 31, 489-498.

Bhattacharya, D., Stickel, S. K. \& Sogin, M. L. (1991). Molecular phylogenetic analysis of actin genic regions from Achlya bisexualis (Oomycota) and Costaria costata (Chromophyta). $J$ Mol Evol 33, 525-536.

Bhattacharya, D., Medlin, L., Wainright, P. O., Ariztia, E. V., Bibeau, C., Stickel, S. K. \& Sogin, M. L. (1992). Algae containing chlorophyll $a+c$ are polyphyletic: molecular evolutionary analysis of the Chromophyta. Evolution 46, 1801-1817; erratum 47 (1993), 986.

Bhattacharya, D., Helmchen, T., Bibeau, C. \& Melkonian, M. (1995a). Comparisons of nuclear-encoded small-subunit ribosomal RNAs reveal the evolutionary position of the Glaucocystophyta. Mol Biol Evol 12, 415-420.

Bhattacharya, D., Helmchen, T. \& Melkonian, M. (1995b). Molecular evolutionary analyses of nuclear-encoded small subunit ribosomal RNA identify an independent rhizopod lineage containing the Euglyphina and the Chlorarachniophyta. $J$ Eukaryot Microbiol 42, 65-69.

Cavalier-Smith, T. (1993). The origin, losses and gains of chloroplasts. In Origins of Plastids, pp. 291-348. Edited by R. A. Lewin. London: Chapman \& Hall.

Cavalier-Smith, T. (1995). Membrane heredity, symbiogenesis, and the multiple origins of algae. In Biodiversity and Evolution, pp. 75-114. Edited by R. Arai, M. Kata \& Y. Doi. Tokyo: The National Science Museum Foundation.

Cavalier-Smith, T. \& Chao, E. E. (1996). 18S rRNA sequence of Heterosigma carterae (Raphidophyceae), and the phylogeny of heterokont algae (Ochrophyta). Phycologia 35, 500-510. 
Cavalier-Smith, T., Allsopp, M. T. E. P. \& Chao, E. E. (1994a). Chimeric conundra: are nucleomorphs and chromists monophyletic or polyphyletic? Proc Natl Acad Sci USA 91, 11368-11372.

Cavalier-Smith, T., Allsopp, M. T. E. P. \& Chao, E. E. (1994b). Thraustochytrids are chromists, not Fungi: 18S rRNA signatures of Heterokonta. Philos Trans R Soc Lond Biol 346, 387-397.

Cavalier-Smith, T., Chao, E. E. \& Allsopp, M. T. E. P. (1995). Ribosomal RNA evidence for chloroplast loss within Heterokonta: pedinellid relationships and a revised classification of Ochristan algae. Arch Protistenkd 145, 209-220.

Daugbjerg, N. \& Andersen, R. A. (1997a). Phylogenetic analyses of the rbcL sequences from haptophytes and heterokont algae suggest their chloroplasts are unrelated. Mol Biol Evol 14, 1242-1251.

Daugbjerg, N. \& Andersen, R. A. (1997b). A molecular phylogeny of the heterokont algae based on analyses of chloroplastencoded rbcL sequence data. J Phycol 33, 1031-1041.

Delwiche, C. F. (1999). Tracing the thread of plastid diversity through the tapestry of life. Am Nat 154, 164-177.

De Rijk, P. \& De Wachter, R. (1993). DCSE, an interactive tool for sequence alignment and secondary structure research. Comput Appl Biosci 9, 735-740.

De Rijk, P. \& De Wachter, R. (1997). RnaViz, a program for the visualisation of RNA secondary structure. Nucleic Acids Res 25, 4679-4684.

De Rijk, P., Wuyts, J., Van de Peer, Y., Winkelmans, T. \& De Wachter, R. (2000). The European large subunit ribosomal RNA database. Nucleic Acids Res 28, 177-178.

Douglas, S. E., Murphy, C. A., Spencer, D. F. \& Gray, M. W. (1991). Cryptomonad algae are evolutionary chimaeras of two phylogenetically distinct unicellular eukaryotes. Nature 350, 148-151.

Eschbach, S., Wolters, J. \& Sitte, P. (1991). Primary and secondary structure of the nuclear small subunit ribosomal RNA of the cryptomonad Pyrenomonas salina as inferred from the gene sequence: evolutionary implications. $J$ Mol Evol 32, 247-252.

Ettl, H. (1978). Xanthophyceae. In Susswasserflora von Mitteleuropa, Bd. 3, 1. Edited by H. Ettl, H. J. Gerloff \& H. Heynig. Stuttgart: Teil, Gustav Fisher.

Felsenstein, J. (1985). Confidence limits on phylogenies: an approach using bootstrap. Evolution 39, 783-791.

Forster, H., Coffey, M. D., Elwood, H. \& Sogin, M. L. (1990). Sequence analysis of the small subunit ribosomal RNAs of three zoosporic fungi and implications for fungal evolution. Mycologia 82, 306-312.

Gajadhar, A. A., Marquardt, W. C., Hall, R., Gunderson, J., AriztiaCarmona, E. V. \& Sogin, M. L. (1991). Ribosomal RNA sequences of Sarcocystis muris, Theileria annulata, and Crythecodinium cohnii reveal evolutionary relationships among apicomplexans, dinoflagellates, and ciliates. Mol Biochem Parasitol 45, 147-154.

Gibbs, S. P. (1981). The chloroplasts of some algal groups may have evolved from endosymbiotic eukaryotic algae. Ann $N Y$ Acad Sci 361, 193-208.

Gibbs, S. P. (1993). The evolution of algal chloroplasts. In Origins of Plastids, pp. 107-121. Edited by R. A. Lewin. London: Chapman and Hall.

Gillott, M. (1990). Phylum Cryptophyta. In Handbook of Protoctista, pp. 139-151. Edited by L. Margulis, J. O. Corliss, M. Melkonian \& D. J. Chapman. Boston, MA: Jones and Bartlett.
Gilson, P. R. \& McFadden, G. I. (1996). The miniaturized nuclear genome of eukaryotic endosymbiont contains genes that overlap, genes that are cotranscribed, and the smallest known spliceosomal introns. Proc Natl Acad Sci US A 93, 7737-7742.

Green, J. C., Perch-Nielsen, K. \& Westbroek, P. (1990). Phylum Prymnesiophyta. In Handbook of Protoctista, pp. 293-317. Edited by L. Margulis, J. O. Corliss, M. Melkonian \& D. J. Chapman. Boston, MA: Jones and Bartlett.

Heywood, P. (1990). Phylum Raphidophyta. In Handbook of Protoctista, pp. 318-325. Edited by L. Margulis, J. O. Corliss, M. Melkonian \& D. J. Chapman. Boston, MA: Jones and Bartlett.

Hibberd, D. J. \& Leedale, G. F. (1970). Eustigmatophyceae: a new algal class with unique organization of the motile cell. Nature 225, 758-760.

Hibberd, D. J. \& Leedale, G. F. (1971). A new algal class: the Eustigmatophyceae. Taxon 20, 523-525.

Hibberd, D. J. \& Leedale, G. F. (1972). Observations on the cytology and ultrastructure of the new algal class, Eustigmatophyceae. Ann Bot 36, 49-71.

Hirt, R. P., Logsdon, J. M., Jr., Healey, B., Dorey, M. W., Doolittle, W. F. \& Embley, T. M. (1999). Microsporidia are related to Fungi: evidence from the largest subunit of RNA polymerase II and other proteins. Proc Natl Acad Sci US A 96, 580-585.

Ishida, K., Green, B. R. \& Cavalier-Smith, T. (1999). Diversification of a chimeric algal group, the chlorarachniophytes: phylogeny of nuclear and nucleomorph small-subunit rRNA genes. Mol Biol Evol 16, 321-331.

Keeling, P. J. \& Doolittle, W. F. (1996). Alpha-tubulin from earlydiverging eukaryotic lineages and the evolution of the tubulin family. Mol Biol Evol 13, 1297-1305.

Kimura, M. (1980). A simple method for estimating evolutionary rates of base substitutions through comparative studies of nucleotide sequences. J Mol Evol 16, 111-120.

Knoll, A. H. (1992). The early evolution of eukaryotes: a geological perspective. Science 256, 622-627.

Lavau, S., Saunders, G. W. \& Wetherbee, R. (1997). A phylogenetic analysis of the synurophyceae using molecular data and scale case morphology. J Phycol 33, 135-151.

Leipe, D. D., Wainright, P. O., Gunderson, J. H., Porter, D., Patterson, D. J., Valois, F., Himmerich, S. \& Sogin, M. L. (1994). The stramenopiles from a molecular perspective: 16S-like rRNA sequences from Labyrinthuloides minuta and Cafeteria roenbergensis. Phycologia 33, 369-377.

Leipe, D. D., Tong, S. M., Goggin, C. L., Slemenda, S. B., Pieniazek, N. J. \& Sogin, M. L. (1996). 16S-like rDNA sequences from Developayella elegans, Labyrinthuloides haliotidis, and Proteromonas lacertae confirm that the stramenopiles are a primarily heterotrophic group. Eur J Protistol 32, 449-458.

Ludwig, M. \& Gibbs, S. P. (1989). Evidence that nucleomorphs of Chlorarachnion reptans (Chlorarachniophyceae) are vestigial nuclei: morphology, division and DNA-DAPI fluorescence. $J$ Phycol 25, 385-404.

McFadden, G. I. (1993). Second-hand chloroplasts: evolution of cryptomonad algae. Adv Bot Res 19, 189-230.

Maerz, M., Wolters, J., Hofmann, C. J., Sitte, P. \& Maier, U. G. (1992). Plastid DNA from Pyrenomonas salina (Cryptophyceae): physical map, genes, and evolutionary implications. Curr Genet 21, 73-81.

Maier, U. G., Hofmann, C. J., Eschbach, S., Wolters, J. \& Igloi, G. L. (1991). Demonstration of nucleomorph-encoded eukaryotic 
small subunit ribosomal RNA in cryptomonads. Mol Gen Genet 230, 155-160.

Martin, W., Stoebe, B., Goremykin, V., Hansmann, S., Hasegawa, M. \& Kowallik, K. V. (1998). Gene transfer to the nucleus and the evolution of chloroplasts. Nature 393, 162-165.

Medlin, L. K., Cooper, A., Hill, C., Wrieden, S. \& Wellbrock, U. (1995). Phylogenetic position of the Chromista plastids based on small subunit rRNA coding regions. Curr Genet 28, 560-565.

Moreira, D., Le Guyader, H. \& Philippe, H. (2000). The origin of red algae: implications for the evolution of chloroplasts. Nature 405, 69-72.

Palmer, J. D. \& Delwiche, C. F. (1998). The origin of plastids and their genomes. In Molecular Systematics of Plants 2, pp. 375-409. Edited by D. E. Soltis, P. S. Soltis \& J. J. Doyle. New York: Chapman and Hall.

Patterson, D. J. (1989). Stramenopiles: chromophyte from a protistan perspective. In The Chromophyte Algae: Problems and Perspectives, pp. 357-379. Edited by J. C. Green, B. S. C. Leadbeater \& W. L. Diver. Oxford: Clarendon Press.

Patterson, D. J. \& Sogin, M. L. (1993). Eukaryote origins and protistan diversity. In The Origin and Evolution of Prokaryotic and Eukaryotic Cells, pp. 13-46. Edited by H. Hartman \& K. Matsuno. River Edge, NJ : World Scientific Publishing.

Philippe, H. \& Germot, A. (2000). Phylogeny of eukaryotes based on ribosomal RNA: long branch attraction and models of sequence evolution. Mol Biol Evol 17, 830-834.

Philippe, H., Lopez, P., Brinkmann, H., Budin, K., Germot, A., Laurent, J., Moreira, D., Müller, M. \& Le Guyader, H. (2000). Early branching or fast evolving eukaryotes? An answer based on slowly evolving positions. Proc Roy Soc Series B 267, 1213-1222.

Potter, D., Saunders, G. W. \& Andersen, R. A. (1997). Phylogenetic relationships of the Raphidophyceae and Xanthophyceae as inferred from nucleotide sequences of the $18 \mathrm{~S}$ ribosomal RNA gene. Am J Bot 84, 966-972.

Ragan, M. A. \& Gutell, R. R. (1995). Are red algae plants? Bot $J$ Linn Soc 118, 81-105.

Saitou, N. \& Nei, M. (1987). The neighbor-joining method: a new method for reconstructing phylogenetic trees. Mol Biol Evol 4, 406-425.

Saunders, G. W., Potter, D., Paskind, M. P. \& Andersen, R. A. (1995). Cladistic analyses of combined traditional and molecular data sets reveal an algal lineage. Proc Natl Acad Sci US A 92, 244-248.

Saunders, G. W., Potter, D. \& Andersen, R. A. (1997). Phylogenetic affinities of the Sarcinochrysidales and Chrysomeridales (Heterokonta) based on analyses of molecular and combined data. J Phycol 33, 310-318.

Silva, P. C. (1980). Names of classes and families of living algae. Regnum Veg 103, 1-156.

Strimmer, K. \& von Haeseler, A. (1996). Quartet puzzling: a quartet maximum likelihood method for reconstructing tree topologies. Mol Biol Evol 13, 964-969.

Swofford, D. L. (1998). PAUP*. Phylogenetic Analysis Using Parsimony (*and Other Methods). Version 4. Sunderland, MA: Sinauer Associates.

Van de Peer, Y. \& De Wachter, R. (1997a). Evolutionary relationships among the eukaryotic crown taxa taking into account site-to-site rate variation in $18 \mathrm{~S}$ rRNA. J Mol Evol 45, $619-630$.
Van de Peer, Y. \& De Wachter, R. (1997b). Construction of evolutionary distance trees with TREECON for Windows: accounting for variation in nucleotide substitution rate among sites. Comput Appl Biosci 13, 227-230.

Van de Peer, Y., Rensing, S. A., Maier, U. G. \& De Wachter, R. (1996a). Substitution rate calibration of small subunit ribosomal RNA identifies chlorarachniophyte endosymbionts as remnants of green algae. Proc Natl Acad Sci US A 93, 7732-7736.

Van de Peer, Y., Van der Auwera, G. \& De Wachter, R. (1996b). The evolution of stramenopiles and alveolates as derived by "substitution rate calibration" of small ribosomal subunit RNA. J Mol Evol 42, 201-210.

Van de Peer, Y., Baldauf, S. L., Doolittle, W. F. \& Meyer, A. (2000a). An updated and comprehensive rRNA phylogeny of (crown) eukaryotes based on rate calibrated evolutionary distances. J Mol Evol 51, 565-576.

Van de Peer, Y., Ben Ali, A. \& Meyer, A. (2000b). Microsporidia: accumulating molecular evidence that a group of amitochondriate and suspectedly primitive eukaryotes are just curious fungi. Gene 246, 1-8.

Van der Auwera, G. \& De Wachter, R. (1997). Complete large subunit ribosomal RNA sequences from the heterokont algae Ochromonas danica, Nannochloropsis salina, and Tribonema aequale, and phylogenetic analysis. J Mol Evol 45, 84-90.

Van der Auwera, G., Chapelle, S. \& De Wachter, R. (1994). Structure of the large ribosomal subunit RNA of Phytophthora megasperma, and phylogeny of the oomycetes. FEBS Lett 338, 133-136.

Van der Auwera, G., De Baere, R., Van de Peer, Y., De Rijk, P., Van den Broeck, I. \& De Wachter, R. (1995). The phylogeny of the Hyphochytriomycota as deduced from ribosomal RNA sequences of Hyphochytrium catenoides. Mol Biol Evol 12, 671-678.

Van der Auwera, G., Hofmann, C. J., De Rijk, P. \& De Wachter, R. (1998). The origin of red algae and cryptomonad nucleomorphs: a comparative phylogeny based on small and large subunit rRNA sequences of Palmaria palmata, Gracilaria verrucosa, and the Guillardia theta nucleomorph. Mol Phylogenet Evol 10, 333-342.

Vossbrinck, C. R., Maddox, J. V., Friedman, S., DebrunnerVossbrinck, B. A. \& Woese, C. R. (1987). Ribosomal RNA sequence suggests microsporidia are extremely ancient eukaryotes. Nature 326, 411-414.

Wainright, P. O., Hinkle, G., Sogin, M. L. \& Stickel, S. K. (1993). Monophyletic origins of the metazoa: an evolutionary link with fungi. Science 260, 340-342.

Whatley, J. M. (1989). Chromophyte chloroplasts: a polyphyletic origin? In The Chromophyte Algae: Problems and Perspectives, pp. 125-144. Edited by J. C. Green, B. S. C. Leadbeater \& W. L. Diver. Oxford: Clarendon Press.

Whatley, J. M. (1993). Membranes and plastid origins. In Origins of Plastids, pp. 77-106. Edited by R. A. Lewin. London: Chapman and Hall.

Williams, D. M. (1991a). Cladistic methods and chromophyte phylogeny. Biosystems 25, 101-112.

Williams, D. M. (1991b). Phylogenetic relationships among the Chromista: a review and preliminary analysis. Cladistics 7 , 141-156.

Zhang, Z., Green, B. R. \& Cavalier-Smith, T. (1999). Single gene circles in dinoflagellate chloroplast genomes. Nature $\mathbf{4 0 0}$, 155-159. 